\title{
SINTESIS LITIUM SILIKAT (Li4SiO4) DARI ABU SEKAM PADI UNTUK KONSOLIDAN BATA
}

\author{
Rizka Rahma Sakti, Riyanto, Nahar Cahyandaru \\ Prodi Kimia Fakultas MIPA Universitas Islam Indonesia \\ Balai Konservasi Borobudur \\ rizkarahmasakti@yahoo.co.id
}

\begin{abstract}
Abstrak : Sintesis litium silikat telah dilakukan sebagai bahan konsolidasi untuk bata. Prekursor yang digunakan adalah litium hidroksida (LiOH.H2O), dan SiO2 yang dihasilkan dari abu sekam padi setelah pencucian menggunakan asam sitrat. Abu sekam padi yang dihasilkan dianalisis kadar unsurnya dengan alat XRF. Litium silikat diujikan sebagai bahan konsolidasi mortar bata dengan konsentrasi larutan 10\% b/v. Mortar dicetak dan dikeringkan selama 28 hari, kemudian mortar diuji kekerasan, porositas, permeabilitas dan kapilaritasnya. Hasil karakterisasi dengan XRF menyatakan bahwa semakin tinggi suhu pembakaran, maka kadar silika yang dihasilkan semakin tinggi. Hasil uji mortar paling baik ditunjukkan pada penggunaan abu sekam padi dari pembakaran 500oC dengan kandungan SiO2 83,60\%, nilai kekerasan 178,50 HL, nilai porositas 26,61\% dengan koefisien kapilaritas 6,37 g.cm-2.s1/2 dan permeailitas 1,61 cm/s.
\end{abstract}

Kata Kunci : sintesis litium silikat, konsolidasi, sekam padi, bata.

\begin{abstract}
SynthesizedLithium silicate as an alternative consolidation material for brickhas been synthesized. The precursors usedwere lithium hydroxide $(\mathrm{LiOH} . \mathrm{H} 2 \mathrm{O})$ and $\mathrm{SiO} 2$ produced from rice husk ash after washing with citric acid. Optimum yield was obtained by varying the mass of $\mathrm{RH}$. The result of the rice husk ash was characterized by XRF. Lithium silicate wastested as a mortar brick consolidation material with a concentration of 10\% w/v. Mortas wasmolded and dried for 28 days, then mortars were tested hardness, porocity, permeability and capilarity. The result of characterization by XRF showed that on increasing combustion temperature then increased the content of silica. The best mortar test result are showed on the use of rice husk ash from a combustion temperature of 500 oC with content of silica 83,60\%, hardness value of 178,50 HL, capillarity coeficient 6,37 g.cm-2.s1/2, permeaility $1,61 \mathrm{~cm} / \mathrm{s}$ and the value of porosity $26,61 \%$.
\end{abstract}

Keywords : synthesis of lithium silicate, consolidation, rice husk, brick.

\section{PENDAHULUAN}

\section{A. Latar Belakang}

Sejak zaman nenek moyang, Indonesia telah memiliki budaya yang tinggi nilai pentingnya. Salah satu wujud peninggalan budaya tersebut adalah bangunan candi. Bangunan candi adalah peninggalan arsitektural yang berasal dari masa klasik Indonesia. Peninggalan-peninggalan yang memiliki nilai sejarah, arsitektur dan budaya harus dilindungi mengingat nilai penting kesejarahan dan identitas bangsa. Perlindungan peninggalan budaya dapat dilakukan melalui tindakan konservasi dan pemugaran.

Material penyusun bangunan Cagar Budaya beraneka ragam jenisnya, salah satunya adalah bata. Bata banyak dipergunakan untuk bahan bangunan Cagar Budaya di wilayah tertentu, misalnya Jawa Timur, Jawa Barat, Bali, Jambi, Riau dan Sumatera Utara. Kondisi Cagar Budaya dengan bahan penyusun bata ketika ditemukan pada umumnya dalam keadaan runtuh dan materialnya hancur. Hal tersebut disebabkan karena sifat fisik bata yang tidak sekuat material lainnya, yaitu mudah rapuh dan sensitif terhadap ancaman faktor perusak alami baik biologi, fisik maupun kimia (Munandar, 2009).

Konservasi benda-benda batu selalu menjadi masalah rumit dan kompleks. Beberapa variabel harus diperhitungkan untuk mengidentifikasi masalah, memilih tindakan konservasi yang diperlukan dan untuk 
memilih bahan serta prosedur yang akan digunakan. Berdasarkan hal tersebut, maka perlu dilakukan proses konsolidasi (penguatan) menggunakan bahan pengikat. Konsolidasi diperlukan untuk memulihkan kekuatan batuan akibat pelapukan.Selain itu, konsolidasi juaga dapat mengembalikan kekuatan batuan seperti aslinya serta dapat mencegah kerusakan lebih lanjut. Bahan konsolidan diharapkan dapat mengisi ruang-ruang batuan yang telah lapuk, mengikat dan mencegah siklus kristalisasi garam. Perawatan yang dilakukan seharusnya cukup murah, mudah diaplikasikan, aman dan ramah terhadap lingkungan, serta efektif untuk beberapa puluh tahun (Doehene dan Price, 2010).

Beberapa bahan konsolidan yang telah diaplikasikan, yaitu polimer organik seperti resin ternyata kurang cocok karena sifatnya yang hidrofobik, sehingga menyebabkan batu menjadi berkurang sifat porositas dan permeabilitasnya. Selain itu, polimer organik tidak dapat meresap sampai bagian dalam struktur batu yang lapuk. Karena kelemahan tersebut, maka kemudian digunakan polimer anorganik. Namun, polimer anorganik seperti kalsium hidroksida $(\mathrm{Ca}(\mathrm{OH}) 2)$, barium hidroksida $(\mathrm{Ba}(\mathrm{OH}) 2)$ dan amonium oksalat ((NH4)2C2O4) hanya digunakan pada lapisan yang sangat dangkal atau dipermukaan benda karena kapasitas penetrasinya yang rendah (Pinto dan Rodgues, 2008). Selain itu, polimer anorganik juga mempunyai kelemahan, yaitu bahan ini berwarna putih; sehingga hanya bisa diaplikasikan pada material yang berwarna putih saja. Oleh karena itu, perlu dilakukan penelitian mengenai bahan konsolidasi pengganti yang lebih efektif dan efisien untuk dapat digunakan pada bata.

Konsolidan dengan bahan dasar silikat (SiO4) menjadi pilihan yang tepat untuk digunakan, sebab silikat merupakan salah satu komponen penyusun dalam bata. Bahan konsolidan berbasis silikat yang telah dikembangkan adalah garam alkali silikat berupa natrium silikat. Bahan ini cukup efektif, tetapi kemudian ditinggalkan karena adanya dampak negatif dalam jangka panjang, yaitu unsur natrium yang dilepaskan setelah proses konsolidasi akan membentuk garam baru dengan anion lain. Garam tersebut berada di dalam pori dan dapat terakumulasi. Dampak negatif tersebut terjadi karena garam natrium apabila terhidrat akan mengalami perubahan volume yang sangat pesat, sehingga mendesak pori dan dapat menyebabkan pengelupasan lapisan terluar batu.

Pada tahun 1987 konsolidan berbahan dasar etil silikat telah diaplikasikan pada batu pasiran dan monumen (sandstone) di Perancis dan menunjukkan batu yang sebelumnya sangat rapuh, tetap kuat setelah 25 tahun. Akan tetapi, etil silikat mempunyai kelemahan, yaitu tidak dapat diaplikasikan pada batu yang basah dengan kondisi kelembaban lingkungan yang tinggi serta batu yang mengandung kalsit dan garam terlarut (Pinto dan Rodrigues, 2008).

Berdasarkan kelemahan-kelemahan tersebut, maka dikembangkan alternatif bahan konsolidan berbahan dasar litium silikat. Litium silikat tidak mengandung gugus hidrofobik, sehingga reaksi dapat berlangsung sepenuhnya dalam lingkungan hidrofilik, proses konsolidasi dapat berlangsung pada permukaan basah (Thorn, 2012). Berdasarkan pada kelebihan tersebut, litium silikat yang dikembangkan dalam penelitian ini akan menggunakan sumber silikat dari alam, yaitu dengan memanfaatkan abu sekam padi. Sekam padi merupakan salah satu sumber penghasil silika setelah dilakukan pembakaran sempurna pada suhu tinggi, yaitu sekitar 500-600 oC (Putro dan Prasetyoko, 2007).

Silika dapat diisolasi dari sekam padi secara sederhana dengan pembakaran, yang didahului dengan perlakuan asam sitrat 5\% untuk dapat menghasilkan silika dengan kemurnian tinggi (Umeda, 2009). Penelitian Gu, dkk., (2013), berhasil menggunakan sekam padi untuk memperoleh nanosilika. Pada penelitian tersebut, sekam padi dicuci dan direfluks menggunakan $\mathrm{HCl}$. Sekam dibakar dengan suhu awal 150-200 oC kemudian dinaikkan menjadi 510-650 oC selama 2,5-3 jam. Silika yang diperoleh diproses fragmentasi ultrasonik dengan tambahan etanol, sehingga diperoleh serbuk nanosilika (Gu, dkk., 2013).

Litium silikat dapat disintesis melalui berbagai proses, salah satunya reaksi antara silika dengan litium hidroksida. Wu, dkk., (2009), melakukan sintesis litium silikat (Li4SiO4) dengan menggunakan LiOH.H2O dan $\mathrm{SiO} 2$ sebagai bahan dasar pembuatannya dan asam sitrat (C6H8O7.H2O) sebagai agen pengkhelat.

Pembuatan litium silikat seringkali menggunakan silika sintesis, untuk mengurangi dampak negatif dari penggunaan bahan kimia sintesis maka diganti 
menggunakan bahan alami yaitu abu sekam padi yang mengandung silika cukup besar. Sehingga litium silikat yang dihasilkan dapat mempunyai dampak yang seminimal mungkin saat diaplikasikan pada Cagar Budaya.

\section{METODE PENELITIAN}

\section{A. ALAT}

Alat yang digunakan pada penelitian ini antara lain, peralatan gelas, hot plate stirrer (Thermo Scientific), timbangan Mettler Toledo AB204-5, magnetic stirrer, ayakan 60 Mesh, ayakan bertingkat (AS 200 controlRETSCH), stone crusher, microwave, Barnstead Thermolyne 1400 furnace, autoclave, XRF Portabel (Olympus DP-2000 High Count Rate), centrifuge (HERMLE Z 206 A), hardness tester Portebel (TIME 5330), deluxe hardness picks (Mineralab), desikator, mortar, dan alu.

\section{B. BAHAN}

Bahan yang digunakan pada penelitian ini antara lain, sekam padi, akuades, asam sitrat (C6H8O7), litium hidroksida monohidrat (LiOH.H2O), indikator $\mathrm{pH}$ universal, kertas saring Whattman No.41 dan sampel bata yang diambil di lingkungan Balai Konservasi Borobudur.

\section{CARA KERJA}

\section{Preparasi Bata}

Bata dihancurkan kasar dan dimasukkan ke stone crusher kemudian disaring menggunakan ayakan bertingkat dengan ukuran serbuk $<0,125$; 0,125-0,250; 0,250-0,500; dan 0,500-1,000 mm. Serbuk bata dengan berbagai ukuran tersebut dibuat mortar dengan berat12 gram yang komposisinya disesuaikan dengan Hukum Fuller Tabel 1.

Tabel 1. Ukuran dan komposisi mortar

\begin{tabular}{|l|c|c|c|c|}
\hline Uhuran (mm) & $<0,125$ & $0,125-D, 280$ & $0,250-0,500$ & $0,500-1,000$ \\
\hline Hess:s (G) & 6,431 & 1,486 & 1,830 & 2,253 \\
\hline
\end{tabular}

\section{Preparasi Sekam Padi}

Preparasi dimulai dengan merendam sekam padi dalam akuades selama 24 jam tanpa pemanasan, selanjutnya dibilas dan dikeringkan pada suhu 105 oC selama 24 jam. Setelah kering dihaluskan dengan cara diblender hingga lolos ayakan ukuran 60 mesh, kemudian dikeringkan kembali pada suhu 105 oC selama 2 jam, lalu disimpan dalam desikator. Serbuk sekam padi ditimbang dengan variasi sebanyak 15, 20 dan 25 gram. Selanjutnya direndam dengan menggunakan larutan asam sitrat 10\% sebanyak $150 \mathrm{~mL}$ dan dipanaskan di autoclave pada suhu
120 oC selama 2 jam. Kemudian disaring menggunakan kertas saring whatman no. 41 dan dibilas menggunakan akuades. Larutan asam diganti dengan akuades lalu dipanaskan kembali dalam autoclave, diulang beberapa tahap hingga memiliki $\mathrm{pH}$ yang sama dengan akuades. Padatan sekam padi dikeringkan pada suhu 105 oC selama 2 jam dan dibakar dengan variasi suhu 500, 550, 600, 650 dan 700 oC hingga membentuk abu.

\section{Sintesis dan analisis Litium Silikat}

Sintesis litium silikat dibuat dengan menggunakan silika dari abu sekam padi. Tahapan ini dimulai dengan mencampur abu sekam padi dengan 20 mL LiOH 0,125 mol dengan perbandingan mol 1:4 pada suhu 90oC dengan pengadukan konstan selama 2 jam. Tahap selanjutnya larutan di centrifuge selama 7 menit $5000 \mathrm{rpm}$. Dipisahkan antara filtrat dengan endapan. Abu sekam padi yang dihasilkan dari proses pembakaran dianalisis kandungan unsurnya dengan menggunakan XRF sebanyak 3 kali pengulangan.

\section{Pembuatan Mortar Bata}

Pembuatan mortar bata dilakukan dengan cara mencampur serbuk batu bata berbagai ukuran Tabel 1. sebanyak 12 gram dengan $4 \mathrm{~mL}$ larutan litium silikat 10\% b/v. Campuran tersebut dimasukkan kedalam cetakan berbentuk kubus dan silinder, kemudian dibiarkan mengeras selama 28 hari pada suhu ruang.

\section{Uji Fisik Mortar bata}

\subsection{Uji Kekerasan}

Pengukuran kekerasan berdasarkan skala mohs dan HL (Hardness Leeb) dengan menggunakan deluxe hardness picks dan portable hardness tester. Pengujian ini menggunakan mortar silinder yang telah berumur 28 hari.

\subsection{Uji Kapilarisasi}

Pengujian kapilaritas dilakukan dengan menggunakan mortar balok berukuran 1,5 cm x 1,5 $\mathrm{cm}$ x $5 \mathrm{~cm}$. Mortar ditimbang untuk mengetahui berat awal. Kemudian mortar diletakkan di atas sampel uji yang mempunyai kapilaritas tinggi yang telah diberi alas atau sekat. Penimbangan dan pengukuran kenaikan air dilakukan setiap rentang waktu 0,5, 10, 20, dan 30 detik, dilanjutkan 1, 2, 5, dan 10 menit, hingga mencapai titik jenuh. Data yang diperoleh dapat digunakan untuk menghitung massa air total, kecepatan rambat, porositas dan permeabilitas mortar. 


\section{HASIL DAN PEMBAHASAN}

\section{Preparasi dan karakterisasi abu sekam padi}

Abu sekam padi dapat digunakan sebagai bahan dasar sintesis litium silikat. Litium silikat dapat disintesis dari bahan baku yang mengandung silika, baik silika sintetik maupun yang berasal dari alam. Pada penelitian ini sumber silika yang digunakan berasal dari bahan alam, yaitu sekam padi yang merupakan bagian terluar dari bulir padi dan memiliki kandungan silika tertinggi apabila dibandingkan dengan hasil pengolahan padi lainnya, seperti bekatul dan jerami.

Silika yang digunakan dalam penelitian ini diperoleh dari sekam padi yang telah mengalami proses pengabuan, dimana sebelum diabukan sekam padi telah mengalami proses pembersihan dengan asam sitrat dengan konsentrasi 10\%. Rendemen abu sekam padi yang dihasilkan dapat diamati dalam 2 .

Tabel 2. Rendemen abu sekam padi (\%)

\begin{tabular}{|c|c|c|c|c|}
\hline \multirow{2}{*}{$\begin{array}{l}\text { Suhu Pentaksaran geke-m ped } \\
\text { (") }\end{array}$} & \multicolumn{3}{|c|}{ Rendemen tou setram padi (x) } & \multirow{2}{*}{ Raterita (X) } \\
\hline & 15 gram & 20 gram & 25 gram & \\
\hline $\mathbf{5 0 0}$ & $2 \pi, 56$ & 29,19 & $\mathbf{Z B , 1 3}$ & 28,30 \\
\hline S5n & 23,11 & 21,14 & 30, 77 & $25, \mathrm{D1}$ \\
\hline 600 & 22,73 & 24,68 & $\mathbf{2}, \mathbf{3 7}$ & 24,26 \\
\hline 650 & 24,95 & 21,45 & $\mathbf{2 0 , 1 4}$ & 22,18 \\
\hline 700 & 21,74 & 25,51 & 22,38 & 23,21 \\
\hline
\end{tabular}

Rendemen abu sekam padi yang dihasilkan sebesar 22,18-28,30\%. Pada pembakaran suhu 500 oC rendemen abu sekam padi yang diperoleh menunjukkan nilai yang paling tinggi, yaitu 28,30\%. Hal ini disebabkan masih adanya karbon yang belum teroksidasi secara sempurna sehingga abu yang dihasilkan lebih banyak jika dibandingkan dengan abu hasil pembakaran pada suhu yang lebih tinggi. Semakin besar suhu pembakaran, maka rendemen yang dihasilkan akan semakin kecil. Namun, pada suhu pembakaran 650 oC rendemen abu sekam padi mempunyai nilai yang paling kecil. Hasil ini dinilai tidak sesuai, karena rendemen terendah dihasilkan pada suhu pembakaran 700 oC. Kesalahan pada saat percobaanyang mungkin terjadi ketika proses penyaringan dilakukan terdapat sekam padi yang terbuang.

Rendemen abu sekam padi yang dihasilkan dari penelitian ini mempunyai nilai lebih tinggi jika dibandingkan dengan penelitian Wannapera, dkk (2008), yang menyatakan bahwa kandungan abu sekam padi yang ada sebesar 17,90\%. Hasil yang diperoleh dari penelitian ini cukup baik, karena memiliki nilai yang lebih tinggi apabila dibandingkan dengan literatur yang ada. Salah satu faktor yang mempengaruhinya adalah tahap pembersihan terhadap sekam padi menggunakan asam sitrat 10\%, sehingga zat-zat pengotor berkurang. Pengotor yang ada biasanya berupa logam anorganik. Untuk mengetahui keberadaan logam-logam pengotor tersebut digunakan instrumen X-ray Fluoresence(XRF). Hasil dari pengujian ini dapat diamati dalam Tabel 3.

Tabel 3. Kandungan Abu Sekam Padi

\begin{tabular}{|c|c|c|c|c|c|c|c|c|}
\hline \multicolumn{3}{|c|}{ Sampel } & \multicolumn{6}{|c|}{ Pengchtrr } \\
\hline 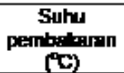 & $\begin{array}{c}\text { Mrrssa } \\
\text { Setrin Pedi } \\
\text { (q) }\end{array}$ & $\begin{array}{l}\text { Warna Abu } \\
\text { Seterm Padi }\end{array}$ & $\mathrm{SO}_{2}$ & $\mathbf{F e}$ & Al & $\mathrm{Ca}$ & $\mathbf{M g}$ & $\mathbf{K}$ \\
\hline \multirow{3}{*}{$\mathbf{5 0 0}$} & 15 & \multirow{3}{*}{ Hbam } & $84, \pi 7$ & 1,1485 & $\mathbf{N D}$ & ND & ND & ND \\
\hline & 20 & & 83,92 & 1,1316 & ND & ND & ND & ND \\
\hline & 25 & & $82,1 \mathrm{D}$ & $1,126 B$ & $\mathbf{N D}$ & ND & ND & $\mathbf{N D}$ \\
\hline \multicolumn{3}{|c|}{ Rotaffitg } & 83,60 & & & & & \\
\hline \multirow{3}{*}{ san } & 15 & \multirow{3}{*}{ Abutabu } & $91, B 1$ & 2,0074 & $\mathrm{ND}$ & ND & ND & ND \\
\hline & 20 & & $89, B 4$ & 2,0704 & $\mathbf{N D}$ & ND & ND & $\mathbf{N D}$ \\
\hline & 25 & & 85,99 & 1,8709 & $\mathbf{N D}$ & ND & ND & ND \\
\hline \multicolumn{3}{|c|}{ Fota-rab } & 89,21 & & & & & \\
\hline \multirow{3}{*}{600} & 15 & \multirow{3}{*}{ Puth } & $93, \mathrm{BB}$ & 2,2536 & $\mathbf{N D}$ & ND & ND & $\mathbf{N D}$ \\
\hline & 20 & & 96,6D & 1,7402 & ND & \begin{tabular}{|l|} 
ND \\
\end{tabular} & ND & ND \\
\hline & 25 & & 99,11 & $2,334 \mathrm{~B}$ & ND & ND & ND & $\mathbf{N D}$ \\
\hline \multicolumn{3}{|c|}{ Roth-fikg } & 96,53 & & & & & \\
\hline \multirow{3}{*}{ exs } & 15 & \multirow{3}{*}{ Puth } & 95,13 & 1,9125 & $\mathbf{N D}$ & ND & ND & $\mathbf{N D}$ \\
\hline & 20 & & 96,99 & 1,1647 & $\mathbf{N D}$ & ND & ND & $\mathbf{N D}$ \\
\hline & 25 & & 98,30 & 1,36n2 & $\mathbf{N B}$ & ND & ND & $\mathbf{N D}$ \\
\hline \multicolumn{3}{|c|}{ Fitaffig } & 96,B1 & & & & & \\
\hline \multirow{3}{*}{700} & 15 & \multirow{3}{*}{ Puth } & 94,76 & 1,3685 & $\mathbf{N D}$ & ND & ND & $\mathbf{N D}$ \\
\hline & 20 & & 99,48 & 1,8439 & ND & ND & ND & ND \\
\hline & 25 & & 99,41 & 1,2537 & ND & ND & ND & ND \\
\hline \multicolumn{3}{|c|}{ Roth-fikg } & 97,B8 & & & & & \\
\hline
\end{tabular}

Keterangan: ND (Not Detected)/tidak terdeteksi

Abu sekam padi merupakan sumber silika (SiO2) yang berasal dari proses pembakaran sekam padi. Pada penelitian ini digunakan sekam padi dengan variasi massa 15, 20 dan 25 gram, serta suhu pembakaran 500, 550, 600, 650 dan 700 oC. Variasi massa dan suhu tersebut berguna untuk mengetahui kadar logam pengotor yang tersisa dalam abu sekam padi setalah sekam padi direndam dengan asam sitrat 10\% sebelum pembakaran.

Hasil analisis XRF yang terdapat dalam Tabel 3. menunjukkan bahwa pengotor anorganik seperti $\mathrm{Al}$, $\mathrm{Ca}, \mathrm{Mg}$ dan $\mathrm{K}$ hilang. Senyawa pengotor dihilangkan dengan cara merendam sekam padi dalam asam sitrat $10 \%$ sebelum proses pembakaran. Pada penelitian Umeda (2008), asam sitrat dengan konsentrasi 5\% terbukti mampu menghasilkan silika dengan kemurnian tinggi sebesar 99,14\% dan bersifat amorf hingga suhu pembakarannya $1000{ }^{\circ} \mathrm{C}$. Oleh karena itu, konsentrasi asam sitrat pada penelitian ini dinaikkan menjadi 10\%, untuk menghasilkan silika dengan nilai kemurnian yang lebih tinggi dan masih bersifat amorf.

Pada Tabel 3. juga dapat diketahui bahwa pengotor Fe masih cukup besar, dimana semakin besar massa sekam padi, maka kadar pengotor Fe semakin kecil, 
sehingga kadar silika yang dihasilkan semakin murni. Oleh karena itu, penggunaan massa sekam padi 25 gram dianggap lebih efisien dan ekonomis untuk menghasilkan silika dibandingkan massa sekam padi 15 dan 20 gram. Namun pada suhu pembakaran 600 oC, penggunaan massa sekam padi sebanyak 25 gram menghasilkan kadar besi sebanyak 2,3348\%. Hal ini menunjukkan adanya peningkatan kadar besi dari penggunaan sekam padi sebanyak 20 gram dengan kadar 1,7402\%. Berdasarkan kenaikan kadar tersebut dimungkinkan terjadi kesalahan pada saat penelitian dilakukan, sehingga diperoleh data yang bertentangan dengan teori. Kadar silika dalam abu sekam padi dapat diamati pada Tabel 3.

Hasil yang terdapat pada Tabel 3. menunjukkan bahwa variasi massa sekam padi hanyaberpengaruh kecil terhadap jumlah silika yang dihasilkan. Pada suhu pembakaran $500^{\circ} \mathrm{C}$ dan $550^{\circ} \mathrm{C}$, semakin besar massa sekam padi yang dibakar, maka kandungan silika yang dihasilkan semakin kecil. Sedangkan pada suhu pembakaran 600,650 dan $700^{\circ} \mathrm{C}$, semakin besar massa sekam padi yang dibakar, maka kandungan silika yang dihasilkan semakin besar. Hal ini disebabkan karena seluruh sekam padi terbakar dengan sempurna yang ditandai dengan adanya abu yang berwarna putih.

Penggunaan variasi suhu pembakaran ternyata cukup besar pengaruhnya terhadap banyaknya sekam padi yang dihasilkan. Hal ini dibuktikan dengan semakin tingginya suhu pembakaran yang digunakan, maka kadar silika rata-rata yang diperoleh akan semakin besar. Pada suhu 500 oC mengasilkan kadar silika rata-rata sebesar 83,60\%, dimana abu yang dihasilkan berwarna hitam. Pada suhu 550 oC kadar silika rata-ratanya naik menjadi 89,21\%. Akan tetapi, abu yang dihasilkan berubah warna menjadi abu-abu. Pada suhu pembakaran 600 oC kadar silika rata-ratanya naik menjadi 96,53\%, kemudian pada suhu 650 oC kadar silika rata-ratanya naik menjadi $96,81 \%$. Kenaikan kadar silika dari suhu pembakaran 600 oC ke 650 oC tidak terlalu besar, yaitu sebesar 0,24\%. Hal ini disebabkan karena pada penggunaan massa sekam padi 25 gram dan suhu pembakaran 650 oC, terjadi penurunan kadar silika. Penurunan kadar silika dapat terjadi karena proses pembersihan dengan asam sitrat 10\% belum maksimal dan sekam padi belum terabukan secara sempurna.Pada suhu pembakaran 700 oC kadar silika rata-rata naik menjadi 97,88\%. Abu yang dihasilkan pada suhu pembakaran 600, 650 dan 700 oC berwarna putih yang menunjukkan bahwa proses oksidasi karbon telah berjalan sempurna. Warna abu yang dihasilkan dapat diamati pada Gambar 2.

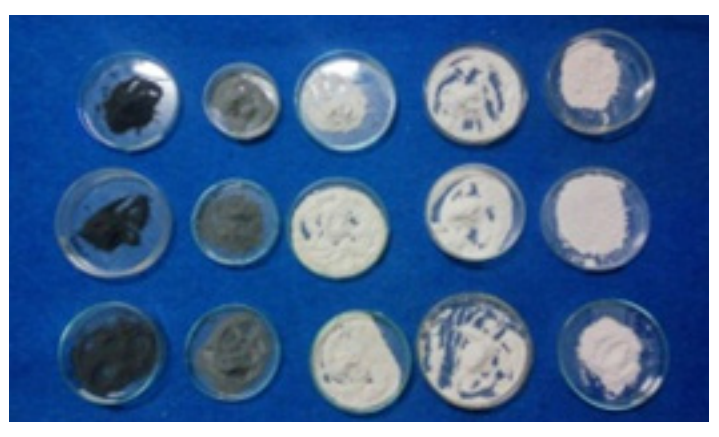

a. b. c. d. e.

Gambar 2. Abu Sekam Padi hasil pembakaran sekam padi

(a)500, (b) 550, (c) 600, (d) 650 dan (e) 700 oC.

Penggunaan variasi suhu pembakaraan menghasilkan silika dengan jumlah yang meningkat, berbanding lurus dengan pertambahan suhu. Hal ini dapat terjadi karena dimungkinkan pengotor yang ada telah terbakar. Semakin tinggi suhu pembakaran, maka pengotor yang tersisa semakin sedikit, sehingga silika yang diperoleh semakin murni.

\section{Hasil Konsolidasi Batu Bata dengan Litium Silikat}

Litium silikat disintesis menggunakan material dasar litium hidroksida monohidrat (LiOH.H2O) dan silika (SiO2) dari abu sekam padi.Sintesis litium silikat digunakan sebagai bahan pengikat (binder) serbuk batu bata dalam pembentukkan mortar.Hasil konsolidasi dapat diamati pada Gambar 3.

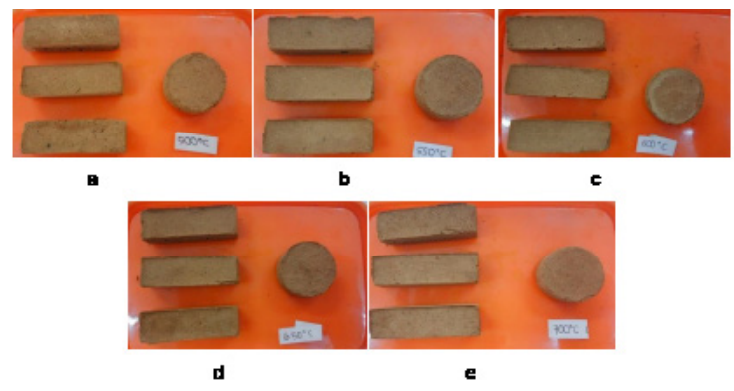

Gambar 3. Mortar dengan $\mathrm{Li} 4 \mathrm{SiO} 4$ variasi pembakaran sekam padi (a) $500 \mathrm{oC}$,

(b) $550 \mathrm{oC}$, (c) $600 \mathrm{oC}$, (d) $650 \mathrm{oC}$, (e) $700 \mathrm{oC}$, dengan bentuk balok dan silinder.

Perbandingan mol litium hidroksida dan mol silika yang digunakan dalam penelitian ini adalah 4:1. Perbandingan 
ini disesuaikan dengan persamaan reaksi yang ada, agar tidak terdapat sisa yang dapat mengganggu tampilan fisik mortar. Hal ini telah dilaporkan oleh Agustina (2016), bahwa perbandingan 4:1 untuk mol litium hidroksida dan silika mampu memberikan hasil mortar terbaik tanpa ada sisa reaktan pada permukaan mortar. Berikut reaksi yang terjadi:

$$
4 \mathrm{LiOH}+\mathrm{SiO} 2 \square \mathrm{Li} 4 \mathrm{SiO} 4+2 \mathrm{H} 2 \mathrm{OZ}
$$

Menurut Thorn (2012), konsolidan perlu dilakukan pengenceran sebesar $10 \% \mathrm{~b} / \mathrm{v}$. Konsolidan pada konsentrasi tersebut paling efektif apabila dibandingkan dengan konsentrasi 20\% yang akan menyebabkan permukaan mortar berwarna lebih gelap. Mortar hasil konsolidasi pada Gambar 3., menampakkan hasil yang sama, yaitu berwarna khas merah bata. Pori pada mortar terbentuk akibat dari penggunaan air sebagai pelarut bahan konsolidan. Air akan menguap pada saat mortar didiamkan pada suhu ruang, sehingga bagian yang sebelumnya diisi oleh air akan menjadi kosong dan terbentuklah pori.

\section{Uji Fisik Mortar Batu Bata}

Pengujian fisik pada mortar dilakukan dengan dua cara, pertama adalah kekerasan dan kapilaritas. Hasil uji kekerasan dapat dilihat dalam Tabel 4.

Tabel 4. Hasil Uji Fisik Mortar Bata

\begin{tabular}{|c|c|c|c|c|c|}
\hline \multirow[b]{2}{*}{$\begin{array}{l}\text { Namr } \\
\text { Semped }\end{array}$} & \multicolumn{2}{|c|}{ Kelkeras:n } & \multirow[b]{2}{*}{ 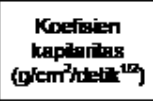 } & \multirow[b]{2}{*}{$\begin{array}{l}\text { Penmenbilhas } \\
\text { (ambltik) }\end{array}$} & \multirow[b]{2}{*}{$\begin{array}{c}\text { Poosings } \\
\text { (K) }\end{array}$} \\
\hline & Mbhs & $\begin{array}{c}\mathrm{HL} \\
\text { (thedress } \\
\text { Lefol) }\end{array}$ & & & \\
\hline Brt $500^{\circ} \mathrm{C}$ & $1-2$ & 178,5 & 1,61 & 26,61 & 6,37 \\
\hline Beth 5xa ${ }^{\circ} \mathrm{C}$ & $1-2$ & $<170$ & 2,17 & 27,43 & 5,33 \\
\hline Befin 600 ${ }^{\circ} \mathrm{C}$ & $1-2$ & $<170$ & 1,72 & 24,32 & 6,00 \\
\hline Beth 650 ${ }^{\circ} \mathrm{C}$ & $1-2$ & $<170$ & 2,14 & 24,49 & 5,21 \\
\hline Beth $700^{\circ} \mathrm{C}$ & $1-2$ & 172,5 & 2,50 & 26,61 & 5,63 \\
\hline Anta Kung & $2-3$ & 246,3 & $5,0 B$ & 32,60 & 1,71 \\
\hline
\end{tabular}

\section{Keterangan: $170 \mathrm{HL}$ adalah limit deteksi alat}

Hasil tersebut menunjukkan bahwa mortar bata pada variasi suhu pembakaran 500oC lebih keras apabila dibandingkan dengan mortar lainnya, yaitu sebesar 178,5 HL. Hal ini dimungkinkan karena silika pada abu sekam padi pembakaran 500 oC masih bersifat amorf, sehingga kereaktifannya lebih besar. Pengujian kekerasan pada penelitian ini dilakukan dengan 2 skala, yaitu Mohs dan HL (Hardness Leeb). Pengukuran dengan skala Mohs hasilnya kurang akurat, sehingga digunakan instrumen tambahan untuk mengukur kekerasan yang terbentuk agar terlihat perbedaannya.

Menurut Kirk dan Othmer (1984), tingkat kereaktifan silika amorf disebabkan karena adanya gugus hidroksil (silanol). Pada kondisi suhu 550700oC, dimungkinkan silika sudah bersifat kristalin, sehingga kereaktifannya menurun yang ditandai dengan berkurangnya kekerasan pada mortar yang dihasilkan. Nilai kekerasan mortar pembakaran sekam padi 500oC tidak terlalu jauh berada di bawah bata kuno, sehingga mortar yang menggunakan litium silikat dapat digunakan sebagai bahan konsolidan alternatif. Apabila mortar memiliki nilai kekerasan yang sama atau bahkan lebih tinggi dari bata kuno, dapat menyebabkan kerusakan pada sisi batu yang yang dikonsolidasi. Hal ini disebabkan sifat mortar yang tidak terlalu keras mortar dan dapat digunakan sebagai pengisi celah retakan, pengisi celah nat batu, bahan kamuflase, bahan pengisi lubang alveol dan untuk merestorasi bagian batu candi yang gempil.

Tabel 4 menunjukkan hasil pengujian kapilaritas yang digunakan untuk mengetahui terbentuknya pori pada mortar. Pori mortar berfungsi untuk meloloskan air pada celah batu diharapkan dapat mencegah pelakukan jangka panjang.Hasil yang disajikan pada Tabel 4. menunjukkan bahwa nilai koefisien kapilaritas yang besar dimiliki oleh mortar bata yaitu 5,21-6,37 g/cm2/detik1/2. Hal ini menandakan bahwa mortar bata memiliki porilebih kecil dibandingkan bata kuno yang nilai koefisien kepilaritasnya lebih kecil. Komposisi serbuk bata yang digunakan untuk membuat mortar bata ditentukan melalui Hukum Fuller yang memperhitungkan nilai kerapatan antar butiran yang mempengaruhi nilai koefisien kapilaritas. Berbeda dengan pembuatan bata kuno dari bahan alam seperti tanah liat, pasir dan kapur tanpa memperhitungkan nilai kerapatan antarbutiran.

Data yang diperoleh dari uji kapilaritas digunakan untuk mengetahui besarnya nilai permeabilitas. Permeabilitas merupakan tingkat kemudahan atau kerapatan mortar untuk dapat dilalui oleh zat cair (air). Semakin kecil permeabilitas mortar, semakin sedikit air yang masuk dalam mortar, semakin awet masa penggunaan mortar.Berdasarkan hasil yang telah dipaparkan dalam Tabel 4. diketahui bahwa nilai permeabilitas mortar bata yang dihasilkam berkisar dari 1,61 sampai 2,50 cm/detik, dan pada bata kuno menunjukkan nilai 5,08 cm/detik. Nilai yang paling kecil ditunjukkan oleh mortar dengan variasi pembakaran sekam padi 500oC yaitu 1,61 cm/ detik. Hal ini dapat diartikan bahwa mortar tersebut merupakan mortar yang paling efektif dan paling baik 
digunakan.

Nilai permeabilitas mortar bata dibandingkan dengan bata kuno menunjukkan perbedaan yang cukup jauh. Hal ini disebabkan karena bata kuno telah mengalami proses pelapukan sehingga bata kuno lebih mudah meloloskan.

Selain permeabilitas, data kapilaritas juga digunakan untuk mengetahui porositas mortar. Berdasarkan Tabel 4, diketahuibahwa mortar bata memiliki porositas sebesar 24,32-27,43\% sedangkan bata kuno sebesar $32,60 \%$. Porositas menunjukkan besar rongga dalam batuan yaitu menggambarkan persentase total ruang yang tersedia yang dapat ditempati fluida. Semakin tinggi nilai porositas, semakin rendah tingkat durabilitas. Semakin tinggi tingkat kepadatan mortar maka semakin besar kuat tekan atau mutu mortar, sebaliknya semakin besar porositas mortar, maka kekuatan mortar akan semakin kecil (Nurwidyanto dkk, 2006). Nilai porositas paling besar ditunjukkan oleh mortar bata dengan variasi pembakaran sekam padi 550 oC yaitu sebesar $27,43 \%$. Nilai porositas mortar bata dan bata kuno menunjukkan nilai yang tidak jauh berbeda. Hal ini menandakan bahwa mortar bata dengan litium silikat yang dihasilkan dapat digunakan sebagai bahan konsolidan alternatif.

\section{KESIMPULAN}

Litium silikat sebagai bahan konsolidan yang dihasilkan dari penggunaan abu sekam padi yang direaksikan dengan litium hidroksida $(\mathrm{LiOH})$ memberikan hasil terbaik pada mortar dengan variasi pembakaran sekam padi suhu $500 \mathrm{oC}$ dengan kandungan silika dalam abunya sebesar 83,60\%, nilai kekerasan 178,5 HL, koefisien kapilaritas $6,37 \mathrm{~g} / \mathrm{cm} 2 /$ detik1/2, permeabilitas $1,61 \mathrm{~cm} /$ detik dan porositas sebesar $26,61 \%$

\section{SARAN}

Perlu dilakukan penelitian lebih lanjut untuk mengetahui kemampuan konsolidasi litium silikat terhadap bata yang lapuk atau dalam keadaan basah. Selain itu perlu dilakukan karakterisasi dengan XRD untuk memastikan sifat silika yang terbentuk dari silika abu sekam padi, sehingga litium silikat dengan silika dari abu sekam padi ini dapat menjadi bahan konsolidan alternatif yang ramah lingkungan.

\section{DAFTAR PUSTAKA}

Agustina, M., 2016, Sintesis Litium Silikat untuk Konsolidasi Batu Andesit di Balai Konservasi Borobudur, Skripsi, Prodi Kimia Universitas Islam Indonesia, Yogyakarta.

Cahyandaru, N., Priyanto, A., Sarman., 2008, Kajian Konservasi Candi Bata di Situs Muara Jambi, Balai Konservasi Peninggalan Borobudur : Magelang.

Choudhary, A., Sahu, B.S., Mazumder, R., Bhattacharyya, S., Chaudhuri, P., 2014, Synthesis and Sintering of $\mathrm{Li4SiO4powder} \mathrm{from} \mathrm{rice} \mathrm{husk}$ ash by solution combustion method and its comparison with solid state method, J. Alloys compd, (590) 440-445.

Dahlan, Hadijaya., 2000, Pengaruh Variasi Beban Indentor Micro Hardness Tester Terhadap Akurasi Data Uji Kekerasan Material, Reaktor Riset ISSN 0852-4777, P2TBDU :Batan.

Doehene dan Price, 2010, Stone Conservation: An Overview of Current Research, The Getty Conservation Institute, Los Angles.

Ekebafe, L.O., Imanah, J.E., and Okieimen F.E. 2010, Physico-mechanical properties of rubber seed shell carbon-filled natural rubber compounds, Chemical Industry andChemical Engineering Quarterly, 16(2) : 149-156.

Ekholm, P., Virkki, L., Ylinen, Maija., Johansson, L., 2003, The Effect of Phytic Acid and Some Natural Chelating Agents on The Solubility of Mineral Elements in Oat Bran, Food Chem., 80(2), 165-170.

Franzoni, E., Pigino, B., Leemann, A., dan Lura, P., 2014, Use of TEOS for Fired-Clay Bricks Consolidation, Mater. Struct., 47(7), 11751184.

Gu, S., Zhou, J., Lou, Z., Wang, Q., Ni, M., 2013, A Detailed Study of The Effects of Pyrolysis Temperature and Feedstock Particle Size on The Preparation of Nanosilica From Rice Husk, J. Ind. Crops Prod, (50) 540-549.

Lumantarna, R., 2012, Material Characterization of New Zealand's Clay Brick Unreinforced Masory Buildings, Thesis, Departemen of Civil and Environmental Engineering The University of Auckland, New Zealand. 
Munandar, Aris. 2009. Kerusakan dan Pelapukan Material Bata. Balai Studi dan Konservasi Borobudur. Magelang.

Nurwidyanto M.I., Meida Y., Sugeng W.2006. Pengaruh Ukuran Butir Terhadap Porositas dan Permeabilitas pada batu Pasir. Jurnal Berkala Fisika. Vol. 9, No.4. Hal. 191-195.

Pinto, A. P. F., dan Rodrigues, J. D., 2008, Stone Consolidation: The Role of Treatment Procedures, J. Cult. Herit., 9(1), 38-53.

Ramli dan Djamas, D., 2007, Pengaruh Pemberian Material Limbah Serat Alami terhadap Sifat Fisika Batu Bata Merah, Padang.

Sembiring, S., Kusuma,V., Ridwan, I.M., dan Halomoan, H., 2011, Sintesis karet alam berpenguat nano silika sekam padi sebagai bahan rubber seal tabung gas elpiji. ProsidingSeminar Nasional Sains \& Teknologi-IV, Bandar Lampung.

Thorn, A., 2012, Lithium Silicate Consolidation of Wet Stone and Plester, Colombia University: New York.

Umeda, J., I. Hisashi, et al. 2009, 'Polysaccharide Hydrolysis and Metallic Impurities Removal Behavior of Rice Husks in Citric Acid Leaching Treatment', 'Transactions of JWRI, Vol 38 (2), pp. 13-18.

Umeda.J., Kondoh.K., 2008,High-PurityAmorphous Silica Originated in Rice Husks viaCarboxylic Acid Leaching Process,J.Mater. Sci.,22 : 70847090 .

Wannapeera J, Worasuwannarak N, Pipatmanomai S., 2008, Product rendemens and characteristics of rice husk. rice straw and corncob during fast pyrolysis in a drop-tube/fixed-bed reactor, Songklanakarin, J. Sci. Technol. Vol. 30(3). hal. 393-404.

Wu, X., Wen, Z., Xu, X., Wang, X., dan Lin, J., 2009, Synthesis and Characterization of Li4SiO4Nano-Powders by a Water-Based SolGel Process, J. Nucl. Mater., 392(3), 471-475. 